\title{
Cowden Disease with Lhermitte-Duclos Disease: Case Report
}

\author{
Sujit S. Prabhu, Kenneth D. Aldape, Janet M. Bruner, Jeffrey S. Weinberg
}

\begin{abstract}
Background: We report a case and review the recent literature describing 36 patients with both Lhermitte-Duclos disease (LDD) and Cowden disease (CD). Lhermitte-Duclos disease, or dysplastic gangliocytoma, is a benign hamartomatous condition involving the cerebellum. The presenting symptoms are usually headaches, gait ataxia, and symptoms of lower cranial nerve involvement. Cowden disease is a rare autosomal dominant disease that usually presents with multiple mucocutaneous lesions. Patients with CD are prone to multiple systemic malignancies, the most common of which is breast cancer. Recent studies have demonstrated an association between LDD and CD. Methods: A 44-year-old woman with a previous history of breast cancer, multiple benign skin lesions, Hashimoto's thyroiditis, and chronic headaches presented with exacerbation of her headaches during the previous year. Magnetic resonance imaging of the brain revealed a right cerebellar nonenhancing mass and an acquired tonsillar herniation. Results: The patient underwent resection of the right cerebellar mass, posterior fossa decompression, $\mathrm{C} 1$ and $\mathrm{C} 2$ laminectomies, and a duraplasty. Pathologic examination confirmed LDD. The patient recovered well after surgery, with immediate improvement of her headaches. Conclusions: The association between LDD and CD has been under-recognized and under-reported. Recognition of this association has direct clinical relevance, because diligent monitoring of individuals with LDD and CD may lead to the early detection of systemic malignancies.
\end{abstract}

RÉSUMÉ: Maladie de Cowden associée à une maladie de Lhermitte-Duclos: cas clinique et revue de la littérature. Introduction : Nous décrivons un cas clinique et nous révisons la littérature concernant 36 patients présentant une maladie de Lhermitte-Duclos (MLD) et une maladie de Cowden (MC). La MLD ou gangliocytome dysplasique est une maladie hamartomateuse bénigne du cervelet. Le patient consulte généralement pour de la céphalée, une ataxie à la marche et des symptômes en relation avec une atteinte des nerfs crâniens inférieurs. La MC est une maladierare, dont l'hérédité est autosomique dominante, dans laquelle les patients présentent de multiples lésions mucocutanées. Les patients ayant une MC sont sujets à de multiples cancers, le plus fréquent étant le cancer du sein. Des études récentes ont montré une association entre la MLD et la MC. Méthodes : Une femme âgée de 44 ans, ayant une histoire antérieure de cancer du sein, de multiples lésions cutanées bénignes, de thyroïdite d'Hashimoto et de céphalées chroniques a consulté pour une exacerbation de ses céphalées depuis un an. L'IRM du cerveau a montré une masse non rehaussante dans la partie droite du cervelet et une hernie amygdalienne acquise. Résultats : La patiente a subi une résection de la masse cérébelleuse droite, une décompression de la fosse postérieure, des laminectomies $\mathrm{C} 1$ et $\mathrm{C} 2$, et une plastie de la dure-mère. L'analyse anatomopathologique a confirmé la présence d'une MLD. La patiente a bien récupéré de sa chirurgie avec une amélioration immédiate de ses céphalées. Conclusions : L'association entre la MLD et la MC a été méconnue et peu rapportée. L'identification de cette association a une pertinence clinique directe puisqu'une surveillance clinique étroite des individus atteints de MLD et de MC peut permettre de détecter plus tôt la présence de cancers.

Can. J. Neurol. Sci. 2004; 31: 542-549

Lhermitte-Duclos disease (LDD), or dysplastic cerebellar gangliocytoma, is a benign hamartomatous tumor of the cerebellum that causes progressive cerebellar dysfunction, which is associated with raised intracranial pressure and noncommunicating hydrocephalus. The prognosis is good if the tumor is resected. ${ }^{1,2}$ In 1920, Lhermitte and Duclos ${ }^{3}$ first described the condition as enlarged folia containing abnormal ganglion cells in circumscribed regions of the cerebellum. Since then, approximately 80 cases have been described in the literature.

Cowden disease (CD), named for the family name of the propositus, was first described by Lloyd and Dennis in $1963 .{ }^{4}$ That patient had skin lesions and benign breast and thyroid tumors, as well as neurologic symptoms of poor coordination and a coarse tremor that were suggestive of cerebellar involvement. Since then, more than 150 cases of $C D$ have been described in the literature. The diagnosis of $\mathrm{CD}$ is established clinically by the presence of pathognomonic mucocutaneous lesions or by a combination of major and minor operational criteria for the diagnosis of CD established by the International Cowden Syndrome Consortium (see Table 1). ${ }^{5}$ Most commonly, the characteristic mucocutaneous lesions include trichilem-

From the Department of Neurosurgery, (SSP, JSW); and the Department of Pathology, (KDA, JMB); The University of Texas M.D. Anderson Cancer Center, The Brain Tumor Center, Houston, Texas, USA

Received February 6, 2004. AcCepted infinalform June 22, 2004.

Reprint requests to: Sujit S. Prabhu, The University of Texas M.D. Anderson Cancer Center, Department of Neurosurgery, The Brain Tumor Center, 1515 Holcombe Blvd., Unit 442, Houston, TX 77030-4009 USA 
momas, papillomatous papules, mucosal lesions, and acral keratosis. In 1981, Russel et $\mathrm{al}^{6}$ described the simultaneous mucocutaneous signs of CD and diffuse cerebellar hypertrophy (LDD) in one patient as a coincidence. In 1991, Padberg et $\mathrm{al}^{7}$ first described the association between the two conditions as a single phakomatosis in two unrelated patients.

The purpose of this report is to describe a case in which the patient had signs and symptoms of both LDD and CD and to analyze the important findings from 36 reported cases. ${ }^{1,2,7-30} \mathrm{It}$ appears that the incidence of $\mathrm{CD}$ is under-reported. Neurosurgeons who treat patients with LDD should be aware of the diagnostic criteria of CD because up to $20 \%$ of patients with LDD may have signs and symptoms suggestive of CD. Also, it is very important to recognize $\mathrm{CD}$ as these patients have an increased risk of developing systemic malignancies and brain tumors.

\section{Case Report}

\section{History and physical examination}

A 44-year-old Caucasian woman presented to the neurosurgical clinic at the University of Texas M.D. Anderson Cancer Center with a five-year history of headaches, which had been exacerbated for the previous year. She also had been diagnosed with infiltrating ductal carcinoma of the breast six years ago and had undergone bilateral mastectomies, chemotherapy, and radiation treatment. She had remained disease-free. The headaches were mainly occipital in distribution, were unrelated to posture, and were not associated with nausea or vomiting. In the past she had multiple wart-like skin lesions (one with histologic features consistent with granuloma annulare and another with features of sclerotic fibroma) and Hashimoto's thyroiditis. Her family history was significant for two sisters with breast cancer, thyroid abnormalities and skin lesions, and father with thyroid and prostate cancer.

On physical examination, the patient was normocephalic and had normal higher-functions. Her Karnofsky performance score was 100, with no cranial nerve deficits. Her motor, sensory and cerebellar functions were normal.

Magnetic resonance imaging (MRI) of the brain revealed a nonenhancing mass in the right cerebellar hemisphere that measured $7 \mathrm{x}$ $6 \times 3 \mathrm{~cm}$. On T1-weighted images, the lesion was hypointense nonenhancing with the administration of gadolinium (Figure 1A). The T2weighted images showed the characteristic feature of LDD, i.e., striations representing the folia of the cerebellum (Figure 2A), along with acquired tonsillar herniation to $\mathrm{C} 2$, and early hydrocephalus (Figure $3 \mathrm{~A}$ ).

\section{Treatment and outcome}

A posterior fossa craniectomy was performed. At surgery, the right cerebellar hemisphere was swollen, and it herniated out when the dura mater was opened. The tumor and normal cerebellum were not clearly demarcated, and the resection was guided by ultrasound. After the tumor was resected, a C1 and C2 laminectomy was performed. The dura mater was opened down to $\mathrm{C} 2$ below the lowest level of tonsillar herniation and a patulous dural graft was placed. The patient's symptoms improved substantially immediately after surgery and, at her four-month follow-up visit, she was asymptomatic. Postoperative MRI demonstrated gross total resection of the lesion, substantial posterior fossa decompression, and the tonsils had ascended to the level of the foramen magnum (Figures 1B, 2B, 3B)
Table 1: International Cowden syndrome consortium operational criteria for the diagnosis of Cowden disease

\section{Criteria category Characteristic}

Pathognomonic Multiple facial trichilemmomas

(Mucocutaneous lesions)Papillomatous papules

Mucosal lesions

Acral keratosis

Major

\author{
Breast cancer \\ Thyroid cancer, especially follicular \\ thyroid carcinoma \\ Macrocephaly \\ Hamartomatous outgrowths of the \\ cerebellum \\ Lhermitte-Duclos disease
}

Minor

Thyroid lesions (e.g. adenoma or goiter)

Mental retardation $(\mathrm{IQ} \leq 75)$

Hamartomatous intestinal polyps

Fibrocystic disease of the breast

Lipomas

Fibromas

Genitourinary tumors or malformations

Operational diagnosis

for individuals
1) Mucocutaneous lesions alone if
a) $\geq 6$ facial papules with $\geq 3$ trichilemmomas,
b)Cutaneous facial papules and oral mucosal papillomatosis
c)Oral mucosal papillomatosis and acral keratoses
d)6 or more palmar/plantar keratoses
2) 2 major criteria, one of which is macrocephaly or Lhermitte-Duclos disease
3) 1 major and 3 minor criteria
or
4) 4 minor criteria

or

or

\section{Histologic features}

Figure 4 shows a low-power (40x) microscopic image of the cerebellar cortex. Abnormal neurons directly under the pial surface essentially replaced the normal molecular layer. Also, the Purkinje cell layer and the granule cell layer were missing. Pathology examination was consistent with dysplastic cerebellar gangliocytoma or LDD.

Immunohistochemical analysis was carried out with staining for PTEN and phospho-akt. Figure 5A shows relative paucity of staining in the lesion for PTEN, however there is positive staining seen in 

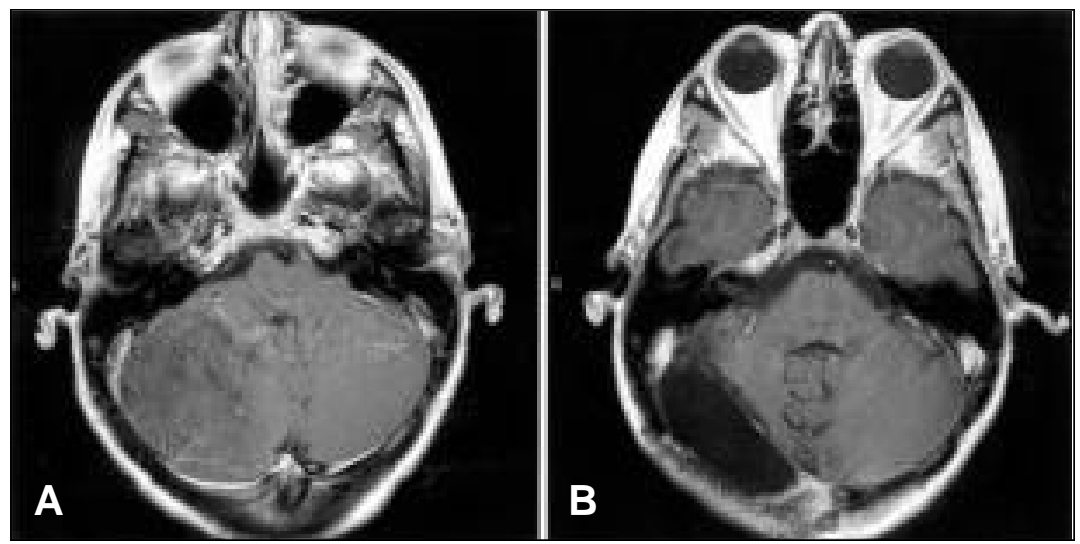

Figure 1A\& B: Axial T1-weighted MR image of the brain after gadolinium, before (Figure 1A) and after (Figure $1 B$ ) resection showing a nonenhancing, relatively hypointense mass in the right cerebellar hemisphere of a patient with Lhermitte-Duclos disease. Compression of the fourth ventricle with resulting ventriculomegaly was present pre-operatively.

Figure 2A\& B: Axial T2-weighted MR image of the brain before (Figure $2 A$ ) and after (Figure $2 B$ ) resection shows a well demarcated mass in the right cerebellar hemisphere, with the characteristic striated appearance, seen in the same patient with Lhermitte-Duclos disease. Compression of the fourth ventricle with resulting ventriculomegaly was present.
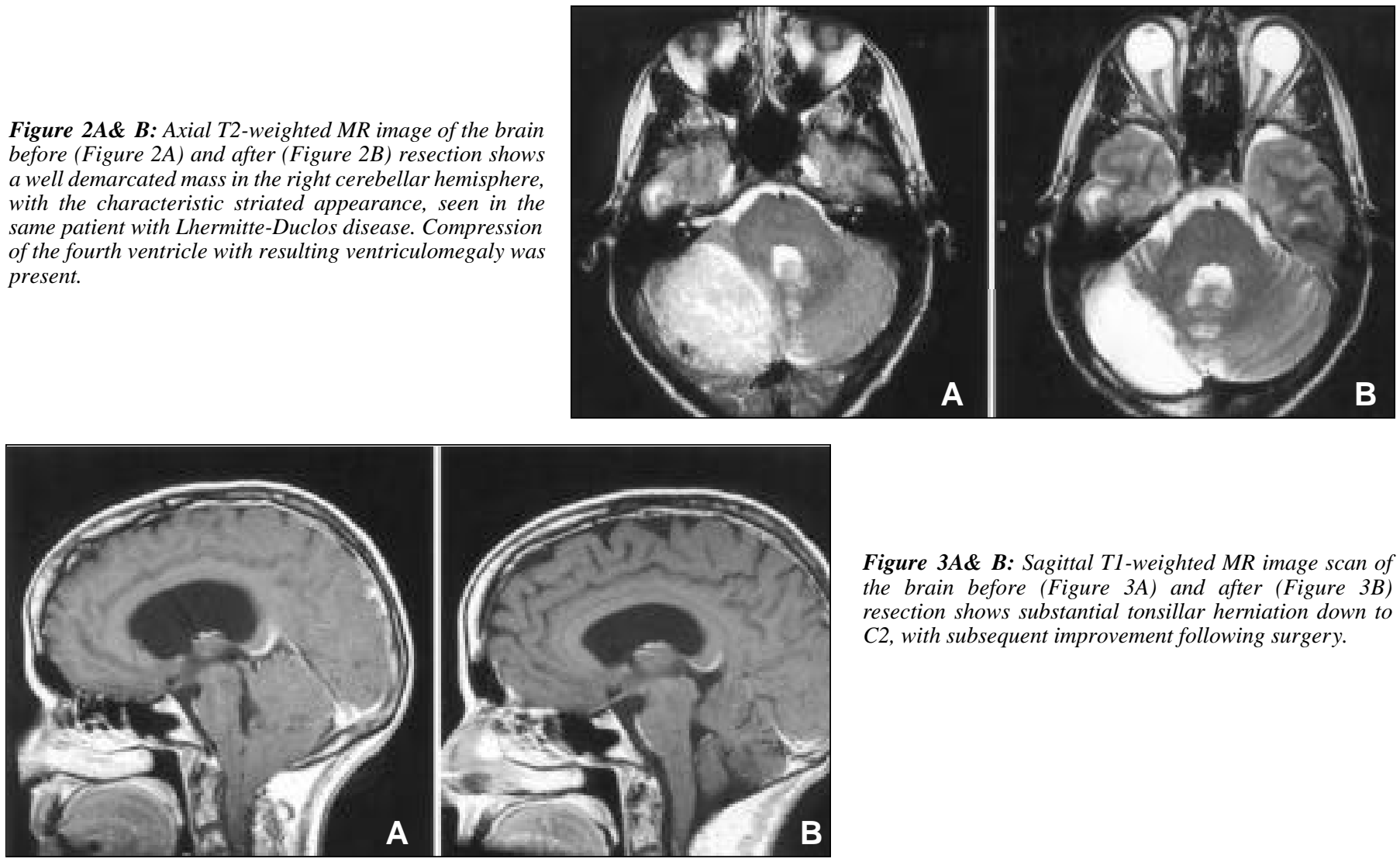

Figure 3A\& B: Sagittal T1-weighted MR image scan of the brain before (Figure 3A) and after (Figure 3B) resection shows substantial tonsillar herniation down to C2, with subsequent improvement following surgery.

Figure 4: Histologic section under low power (40x) shows microscopic image of the cerebellar cortex. Abnormal neurons found just under the pial surface, essentially replace the normal molecular layer. Also, the Purkinje cell layer and the granule cell layer are missing.

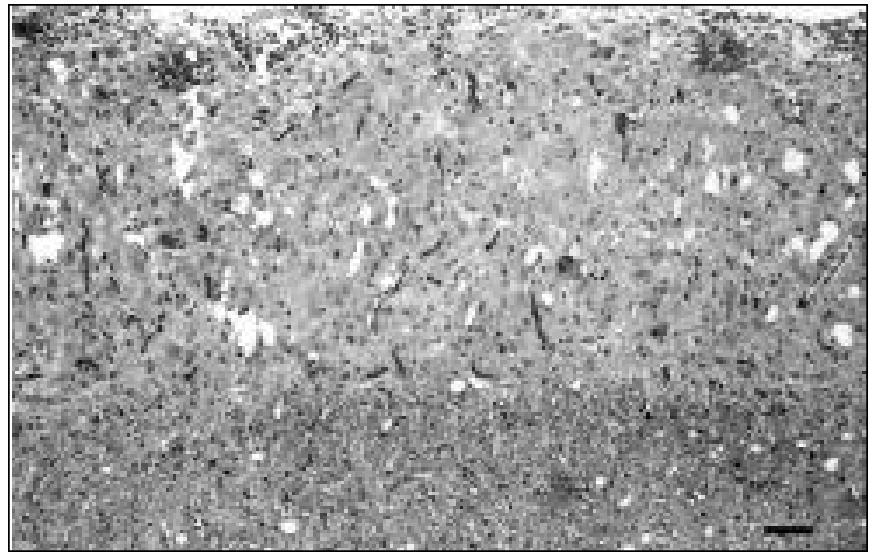


Table 2: Characteristics of $37^{\mathrm{a}}$ patients with both Cowden disease and Lhermitte-Duclos disease ${ }^{b}$

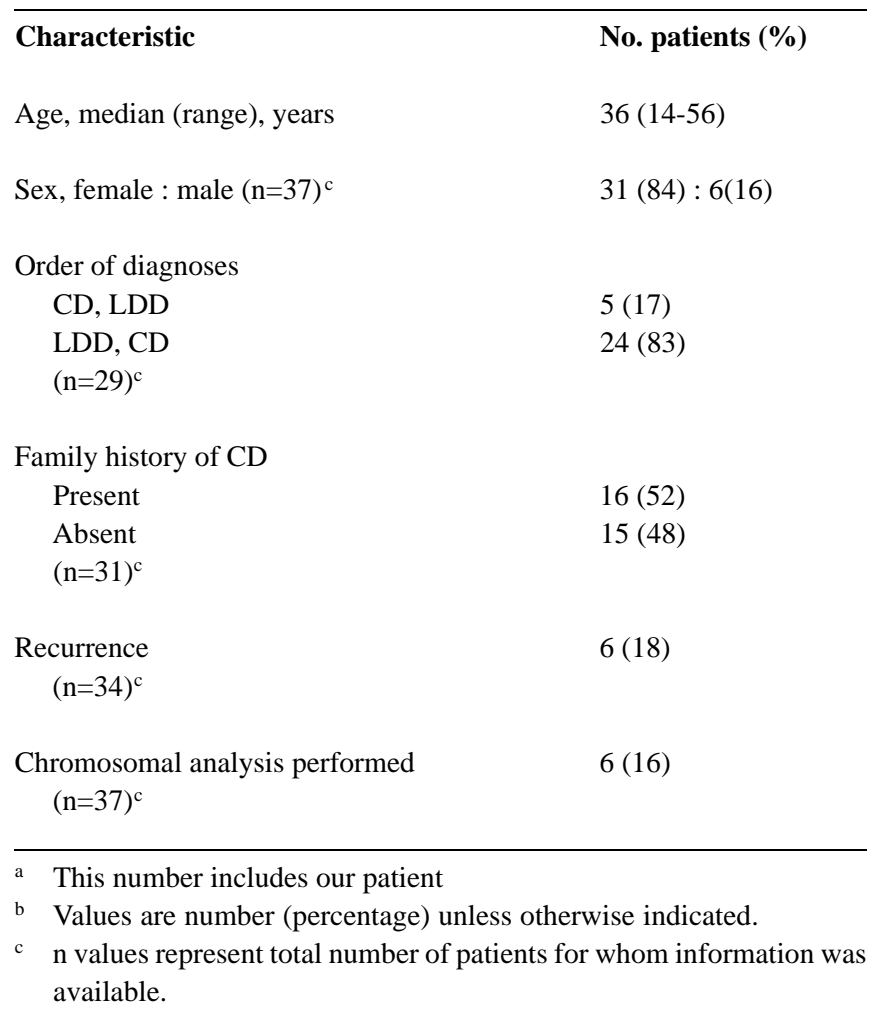

endothelial cells (serves as an internal control). In Figure 5B phosphoakt shows strong nuclear and cytoplasmic positivity in the abnormal neurons. Immunohistochemical staining was performed as previously described. ${ }^{31}$ Following de-paraffinization, antigen retrieval in $10 \mathrm{mM}$ sodium citrate $\mathrm{pH} 6.0$ was performed. Primary antibodies to p-AKT (1200, Cell Signaling Technologies) and PTEN (1-1000, Cascade Biologicals) were applied and incubated overnight at $4^{\circ} \mathrm{C}$. Signal was detected using the Envision system (Dako) followed by diaminobenzidine.

Given her diagnosis and family history, the patient and her sister have been referred to the department of cancer prevention for further work-up.

\section{Discussion}

Cowden disease can be diagnosed on the basis of pathognomonic skin lesions as listed in Table $1 .{ }^{32} \mathrm{~A}$ significant number of patients with CD develop systemic malignancies, $50 \%$ to $80 \%$ of patients exhibit macrocephaly, and approximately $10 \%$ have cognitive impairment. ${ }^{33}$ Most patients with LDD present with symptoms of raised intracranial pressure and ataxia. The other manifestations of LDD are macrocephaly, intellectual impairment, and seizures. ${ }^{34}$

Lhermitte-Duclos disease and CD are both heredofamilial diseases. In a review of 34 cases of LDD, Ambler et a ${ }^{35}$ described the first familial association of the tumor in both mother and son. The mother died of metastatic breast carcinoma; by current diagnostic criteria she would be considered to have $\mathrm{CD}$. The son had seizures, and both patients had macrocephaly and mental retardation, consistent with $\mathrm{CD}$. The familial occurrence of CD is well-described by Starink et al, ${ }^{33}$ and more recently Eng et $\mathrm{al}^{13}$ described a three-generation family with clinical features of both LDD and CD.

Cowden disease is an autosomal dominant disorder, with a high penetrance in both sexes; it may also occur spontaneously. ${ }^{33}$ In 1996, the CD locus was mapped to human chromosome $10 \mathrm{q} 22-23$, which is also the locus for the tumor suppressor gene PTEN (the phosphatase and tensin homologue deleted on chromosome 10; also called MMAC1). ${ }^{5}$ Most of the tumorsuppressive properties of PTEN are dependent on its lipid phosphatase activity, which inhibits the phosphatidylinositol-3'kinase (PI3K) Akt signaling pathway through dephosphorylation of phosphatidylinositol-[10,11,35]-triphosphate. ${ }^{36}$

Cowden disease is inherited as a germline mutation and patients who inherit CD in this fashion have a defective PTEN tumor suppressor gene that is present on one allele in every cell in the body. ${ }^{15,20,37}$ The occurrence of LDD is predicted to occur
A

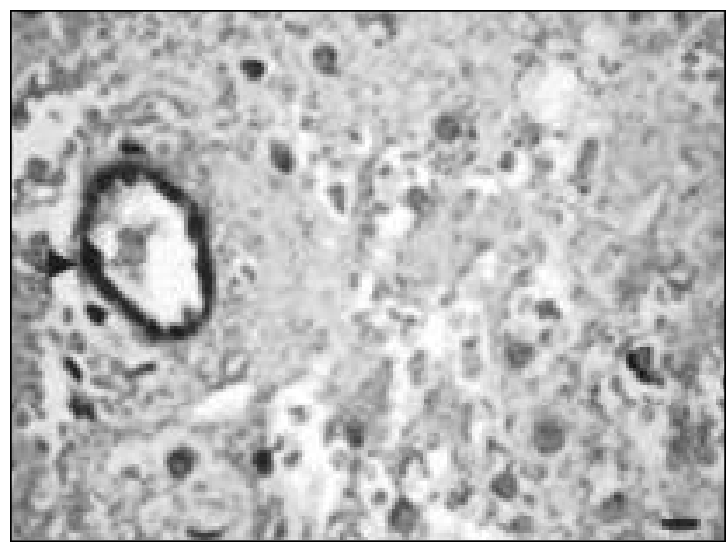

B

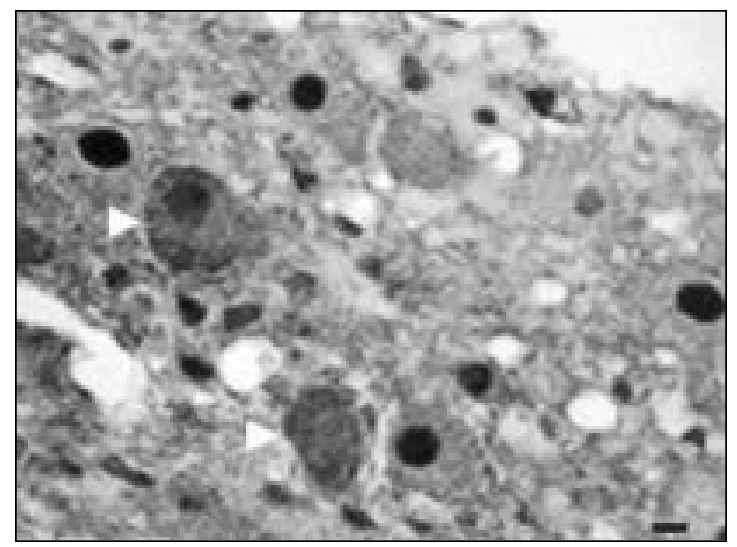

Figure 5A \& B: Immunohistochemistry shows relative paucity of staining in the lesion for PTEN, however, there is positive staining seen in endothelial cells (black arrow serves as an internal control). Phospho-akt shows strong nuclear and cytoplasmic positivity in the abnormal neurons (white arrow). 
after an additional somatic hit on either the remaining normal CD allele or another unknown gene. ${ }^{5,15,37,38}$ Cowden disease is currently diagnosed on the basis of clinical features alone, and the chromosomal analysis for the defective PTEN tumor suppressor gene contributes to the diagnosis. In our review of the literature six (16\%) of 36 patients tested positive for the defective PTEN tumor suppressor gene, and more than half of the cases had a family history of both LDD and/or CD (Table 2). These symptomatic family members should be closely monitored, because of the increased risk of developing systemic malignancies.

Immunohistochemical analysis in our patient showed a diminished staining for PTEN; however, there was a strong nuclear and cytoplasmic positivity in the abnormal neurons when stained with phospho-Akt (Figure 5). This indicates a defective function of PTEN and confirms the negative regulatory function of PTEN on the PI3/Akt pathway seen in our patient.

The incidence of CD in patients with LDD is still unclear. In a review of the literature, Vinchon et $\mathrm{al}^{26}$ found 72 cases of LDD. Twenty-six of these patients had signs and symptoms suggesting $\mathrm{CD}$, and seven had confirmed $\mathrm{CD}$, thus $7 / 33$ cases (21\%) of LDD had CD. Lhermitte-Duclos disease may occur either as sporadic, isolated disease or in association with $\mathrm{CD} .{ }^{26}$ Murata et al ${ }^{18}$ concluded in a review article on LDD that approximately $60 \%$ of cases of LDD occur sporadically without association with CD.

Lhermitte-Duclos disease and CD appear to occur with different prevalences in the two sexes. The incidence of CD alone is higher in females than in males. ${ }^{33}$ The incidence of LDD and $\mathrm{CD}$ in our review was significantly higher in females $(84 \%)$ than in males $(6 \%)$ (Table 2). Interestingly, Ambler et al ${ }^{35}$ noted that LDD alone was more prevalent in males and this was further confirmed by Vichon et al. ${ }^{26}$

In the review by Ambler et al, ${ }^{35}$ the mean age at the diagnosis of LDD alone was 34 years, and the patients showed symptoms of raised intracranial pressure and ataxia. The age of onset of signs and symptoms of patients with LDD in our review was 36 years; the most common symptoms, in decreasing order of incidence, were headaches (58\%), ataxia (45\%), and macrocephaly (45\%) (Table 3). Obstructive hydrocephalus accompanying the cerebellar mass was seen in $53 \%$ of the patients, and over $90 \%$ of the patients with hydrocephalus presented with headaches. The other symptoms included diplopia (13\%), dizziness (9\%), vertigo (6\%), tinnitus $(3 \%)$, facial sensory disturbances $(3 \%)$, dysarthria (3\%), paresis of 7 th nerve $(3 \%)$ and hypacusia $(3 \%)$.

Starink et al $^{33}$ reported that mucocutaneous lesions were the most constant and characteristic finding (100\% incidence), usually in the second decade of life in 21 patients with CD. Macrocephaly was the most common extracutaneous manifestation (80\% incidence). In our review, mucocutaneous trichilemmomas and mucosal papules were the most common dermatologic manifestations. An absence of these dermatologic lesions, however, does not preclude the diagnosis of $\mathrm{CD}$ for patients with LDD.$^{20}$ Macrocephaly, like LDD is a major criterion for the clinical diagnosis of CD (see Table 1) and was seen in 45\% of the patients reviewed. Most of the patients (86\%) had skin and mucosal lesions; other lesions, in decreasing order of incidence, were lesions of the breast $(62 \%)$, thyroid $(57 \%)$, gastrointestinal tract $(22 \%)$, uterus $(19 \%)$, and ovary (16\%) (see Table 3$)$. Table 3: Radiologic and clinical features in $37^{\mathrm{a}}$ patients with
both Lhermitte-Duclos disease and Cowden disease

\begin{tabular}{|c|c|}
\hline Feature & No. patients $(\%)$ \\
\hline \multicolumn{2}{|l|}{ Radiologic finding $(\mathrm{n}=30)^{\mathrm{b}}$} \\
\hline Left cerebellar mass & $13(43)$ \\
\hline Right cerebellar mass & $8(29)$ \\
\hline Cerebellar mass with hydrocephalus & $16(53)$ \\
\hline Hemispheric mass with vermian involvement & $4(13)$ \\
\hline Cerebellar mass with Chiari malformation & $3(10)$ \\
\hline \multicolumn{2}{|l|}{ Other tumors } \\
\hline Meningioma & $2(6)$ \\
\hline Astrocytoma & $1(3)$ \\
\hline \multicolumn{2}{|l|}{ Symptoms at presentation $(\mathrm{n}=31)^{\mathrm{b}, \mathrm{c}}$} \\
\hline Headaches & $18(58)$ \\
\hline Ataxia & $14(45)$ \\
\hline Macrocephaly & $14(45)$ \\
\hline Seizures & $4(13)$ \\
\hline Mental retardation & $4(13)$ \\
\hline Diplopia $^{b}$ & $4(13)$ \\
\hline \multicolumn{2}{|l|}{ Organs involved $(n=37) b, d$} \\
\hline Skin and mucosal lesions & $32(86)$ \\
\hline Breast & $23(62)$ \\
\hline Thyroid & $21(57)$ \\
\hline Gastrointestinal tract & $8(22)$ \\
\hline Uterus & $7(19)$ \\
\hline Ovary & $6(16)$ \\
\hline \multicolumn{2}{|l|}{ Malignancies (n-37) } \\
\hline Breast & $9(24)$ \\
\hline Thyroid & $3(8)$ \\
\hline Gastrointestinal tract & $1(2)$ \\
\hline Uterus & $1(2)$ \\
\hline Kidney & $1(2)$ \\
\hline Liposarcoma & $1(2)$ \\
\hline
\end{tabular}

a This number includes our patient

b $\mathrm{n}$ values represent total number of patients for whom information was available.

c Other symptoms at presentation were dizziness, 3 (9\%); vertigo, 2 (6\%); tinnitus, 1 (3\%); sudden loss of consciousness, $1(3 \%)$; enlarging scalp mass (meningioma), $1(3 \%)$; paresis of the 7 th nerve, 1 (3\%); syncope, 1 (3\%); left hemiparesis, $1(3 \%)$; hypoacusia, $1(3 \%)$.

d Other organs involved were the lung, 1 (2\%); intra-abdominal, 1 (2\%); cystic hygroma, 1 (2\%); eye, 1 (2\%), kidney, 1 (2\%).

Although LDD was originally described as a pathologic entity, Eng et $\mathrm{a}^{13}$ reported a case of a mother and daughter with a family history of both LDD and CD. Neither of these patients had a cerebellar mass, however their signs and symptoms included megalencephaly, macrocephaly, mental retardation, seizure disorder, and ataxia. Eng et $\mathrm{al}^{13}$ argue that both the patients had 
LDD by clinical criteria alone, although the classic pathognomonic anatomic sign of cerebellar hypertrophy was absent. They also postulated that patients with $\mathrm{CD}$ who present with clinical symptoms suggestive of LDD should be monitored because the anatomic substrate of LDD (i.e., a cerebellar mass) may occur at a later date. Thomas and Lewis ${ }^{24}$ also described a similar patient without a cerebellar mass to Eng et al. ${ }^{13}$ The exact cause of the neurologic signs and symptoms in these patients is unclear.

The benign systemic manifestations of $\mathrm{CD}$ usually involve the skin, breast, and thyroid. The skin lesions seen in our patient were granuloma annulare and sclerotic fibroma. The association between sclerotic fibromas and $\mathrm{CD}$ was first reported by Weary et $\mathrm{al}^{39}$ in 1972 and sporadic reports of sclerotic fibromas have since been published. Our report is the second case in which the patient had a sclerotic fibroma with a diagnosis of both LDD and CD. ${ }^{39}$ About $50 \%$ of patients with CD present with fibrocystic disease of the breast, and $60-70 \%$ of patients present with a thyroid goiter and/or adenoma. ${ }^{33}$ Our review indicated a slightly higher incidence of breast involvement (62\%) compared with thyroid involvement $(57 \%)$ in patients with CD. Follicular adenoma is the most common thyroid disorder seen in patients with CD. Hashimoto's thyroiditis (seen in our case) is rarely associated with $\mathrm{CD}$; previous reports ${ }^{33}$ indicate an incidence of $3-4 \%$ in patients with $\mathrm{CD}$.

Our patient had intraductal carcinoma of the breast, which is commonly seen in patients with CD. Most patients are relatively young at presentation and are frequently diagnosed at less than 35 years of age. In an earlier review by Starink et $\mathrm{al}^{33}$ of patients with $\mathrm{CD}$, the incidence of breast carcinoma was $22 \%$; in a separate, more recent study, approximately $30-50 \%$ of women with CD developed carcinoma of the breast. ${ }^{40}$ Breast carcinoma was bilateral in one-third of these women ${ }^{40}$ and, thus, some authors propose prophylactic subcutaneous mastectomies, especially in cases in which a carcinoma has been diagnosed in one breast. The patient in our report had been diagnosed with breast cancer at 35 years of age and had been treated with bilateral mastectomies. In our review of cases of both LDD and $\mathrm{CD}$, the incidence of breast cancer was $24 \%$ (see Table 3 ).

Information about the timing of the diagnosis of $\mathrm{CD}$ was available for 29 patients with both LDD and CD in our review. In 24 patients $(83 \%) \mathrm{CD}$ was diagnosed after LDD was, and in only five patients (17\%) CD was diagnosed before the LDD was. Our review of the literature indicated that approximately $20 \%$ of the patients with LDD may also have CD and, hence, neurosurgeons should work up patients with LDD for a possible diagnosis of $\mathrm{CD}$. We believe a diagnosis of either one of these two disorders should prompt a more comprehensive search for the other, because of the increased risk of systemic malignancies. Patients diagnosed with LDD and CD and their families should be kept under close observation and should undergo regular physical examinations and mammography.

Although LDD is described as a benign hamartomatous lesion involving the cerebellum, six of 34 patients (18\%) had a recurrence after the initial surgery. ${ }^{2,8,12,23,29}$ Although the median age for the diagnosis of LDD in our study was 36 years, two patients were nine and 11 years old at diagnosis., ${ }^{2,23}$ Surgery remains the treatment of choice, and the role of radiation therapy in these cases of recurrent tumors is still unclear. Malignant transformation of LDD tumors has not yet been described.
Magnetic resonance imaging is the gold standard modality for the diagnosis of LDD. ${ }^{41}$ Typically, as the pathognomonic radiographic feature in $\mathrm{LDD},{ }^{17,41}$ the thickened folia of the cerebellum are well-demarcated and appear striated on magnetic resonance imaging. This finding was also noted in our case (Figure 2B). Magnetic resonance imaging is also sensitive in identifying Chiari malformations in the posterior fossa and syringomyelia. ${ }^{42-45}$ Although secondary tonsillar herniation in patients with LDD has been well-described, their incidence is unknown ${ }^{46}$ In our patient, the tonsillar herniation reached to the top of $\mathrm{C} 2$; this degree of a tonsillar descent in patients with both LDD and CD has not previously been described. In this review we identified three patients $(10 \%)$ with tonsillar herniation, including ours, ${ }^{28,47}$ all of whom presented with headaches. A patient, reported by Lindboe et al, ${ }^{16}$ who presented with headaches had an enlarging scalp mass secondary to a convexity meningioma. Headache is the most common presenting symptom of LDD reported to occur in 58\% of patients.

Our patient was treated with a posterior fossa craniectomy and tumor resection. The foramen magnum and upper brainstem were then decompressed by performing $\mathrm{C} 1$ and $\mathrm{C} 2$ laminectomies and a duraplasty. This relieved the cervicomedullary compression, and the patient's symptoms improved substantially. Some authors believe that removal of a posterior fossa mass allows the cerebellar tonsils to ascend. However, we performed a $\mathrm{C} 1$ and $\mathrm{C} 2$ laminectomy and then the duraplasty because our patient's symptoms were secondary to the Chiari malformation and because the cerebellar tonsils had severely descended. Tuli et $\mathrm{a}^{34}$ performed a craniectomy, as well as a $\mathrm{C} 1$ laminectomy, followed by a decompressive duraplasty, in all patients with LDD to optimally improve symptoms and because the lesion cannot be totally resected as a result of poorly defined margins.

Meningiomas have been reported in several patients with CD, with a prevalence of approximately $3 \% .^{2,16,22}$ In our review of patients with LDD and $\mathrm{CD}$, the incidence of intracranial meningiomas was $7 \%$. Lyons et a ${ }^{48}$ concluded that patients with CD have a 1000 -fold increased risk of developing meningiomas. An increased incidence of meningiomas is characteristic of neurofibromatosis 2 , for which the genetic defect has been traced to a locus on the long arm of chromosome 22. The PTEN gene (a tumor suppressor gene similar to neurofibromatosis 2) responsible for $\mathrm{CD}$, however, has not been shown to play a substantial role in the pathogenesis of sporadic meningiomas. ${ }^{49}$ Two cases of astrocytoma and LDD have been previously described. ${ }^{50,51}$ In this report, we identified an additional patient who underwent a partial resection of a third ventricular tumor, which was identified as a pilocytic astrocytoma. ${ }^{26}$ This is the only report of a patient with an astrocytoma and a diagnosis of both LDD and CD. There is no evidence to suggest that the incidence of astrocytic brain tumors is higher in patients with LDD and CD than in the general population. Nevertheless, regular brain radiographic follow up examinations should be performed in all patients with both LDD and CD to identify an LDD recurrence or the development of a de novo brain tumor, especially a meningioma.

As more than $80 \%$ of the patients in this review were diagnosed with $\mathrm{CD}$ after they were diagnosed with LDD, we believe that $\mathrm{CD}$ remains under-diagnosed and possibly underreported. Patients with LDD should be closely examined for the 
mucocutaneous signs of $\mathrm{CD}$, which usually antedate the diagnosis of LDD. Once a diagnosis of CD is established, close surveillance is imperative because these patients have an increased risk of developing systemic malignancies. The patients should also be monitored for LDD recurrence and the possibility of de novo brain tumors. New-onset headaches in a patient with CD should be thoroughly investigated because of the possibility of LDD, other brain tumors, or tonsillar herniation. It is imperative that the neurosurgeons be aware of the clinical stigmata of CD in cases in which the patient presents initially with a posterior fossa mass and LDD. Surgical intervention in patients with LDD and secondary Chiari malformation should include suboccipital craniectomy, foramen magnum decompression, and cervical laminectomy to the lowest level of tonsillar herniation, and duraplasty.

\section{ACKNOWLedGMents}

The authors thank Yvette Martinez for her editorial assistance, and Dr. Weiming Shi for his assistance with figure preparation.

\section{REFERENCES}

1. Koch R, Scholz M, Nelen MR, et al. Lhermitte-Duclos disease as a component of Cowden's syndrome. Case report and review of the literature. J Neurosurg 1999; 90: 776-779.

2. Robinson S, Cohen AR. Cowden disease and Lhermitte-Duclos disease: characterization of a new phakomatosis. Neurosurgery 2000; 46: 371-383.

3. Lhermitte J, Duclos P. Sur un ganglonneurome diffus du certex du vervelet. Bull Assoc Fr Etud Cancer 1920: 99-107.

4. Lloyd KM, 2nd, Dennis M. Cowden's disease. A possible new symptom complex with multiple system involvement. Ann Intern Med 1963; 58: 136-142.

5. Nelen MR, Padberg GW, Peeters EA, et al. Localization of the gene for Cowden disease to chromosome 10q22-23. Nat Genet 1996; 13: 114-116.

6. Russel J, O’Brien M, Wells R. Cowden's Syndrome. Br J Dermatol 1981; 105: 57-58.

7. Padberg GW, Schot JD, Vielvoye GJ, et al. Lhermitte-Duclos disease and Cowden disease: a single phakomatosis. Ann Neurol 1991; 29: 517-523.

8. Albrecht S, Haber RM, Goodman JC, et al. Cowden syndrome and Lhermitte-Duclos disease. Cancer 1992; 70: 869-876.

9. Amagasa M, Yuda F, Tsunoda T, et al. Lhermitte-Duclos disease associated with Cowden disease. Brain Tumor Pathol 1997; 14: 63-69.

10. Barone F, Noubari BA, Torrisi A, et al. Lhermitte Duclos disease and Cowden disease: clinical, pathological and neuroimaging study of a case. J Neurosurg Sci 2000; 44: 234-237.

11. Braud AC, de Rocquancourt A, Marty M, et al. Cowden disease and Lhermitte Duclos disease, markers of breast carcinoma: report of two patients. Ann Oncol 1999; 10: 1241-1243.

12. Chapman MS, Perry AE, Baughman RD. Cowden's syndrome, Lhermitte-Duclos disease, and sclerotic fibroma. Am J Dermatopathol 1998; 20: 413-416.

13. Eng C, Murday V, Seal S, et al. Cowden syndrome and LhermitteDuclos disease in a family: a single genetic syndrome with pleiotropy? J Med Genet 1994; 31: 458-461.

14. King MA, Coyne TJ, Spearritt DJ, et al. Lhermitte-Duclos disease and Cowden disease: a third case. Ann Neurol 1992; 32: 112-113.

15. Liaw D, Marsh DJ, Li J, et al. Germline mutations of the PTEN gene in Cowden disease, an inherited breast and thyroid cancer syndrome. Nat Genet 1997; 16: 64-67.

16. Lindboe CF, Helseth E, Myhr G. Lhermitte-Duclos disease and giant meningioma as manifestations of Cowden's disease. Clin Neuropathol 1995; 14: 327-330.

17. Meltzer CC, Smirniotopoulos JG, Jones RV. The striated cerebellum: an MR imaging sign in Lhermitte-Duclos disease (dysplastic gangliocytoma). Radiology 1995; 194: 699-703.
18. Murata J, Tada M, Sawamura Y, et al. Dysplastic gangliocytoma (Lhermitte-Duclos disease) associated with Cowden disease: report of a case and review of the literature for the genetic relationship between the two diseases. J Neurooncol 1999; 41: 129-136.

19. Murray C, Shipman P, Khangure M, et al. Lhermitte-Duclos disease associated with Cowden's syndrome: case report and literature review. Australas Radiol 2001; 45: 343-346.

20. Nelen MR, Kremer H, Konings IB, et al. Novel PTEN mutations in patients with Cowden disease: absence of clear genotypephenotype correlations. Eur J Hum Genet 1999; 7: 267-273.

21. Ortiz O, Bloomfield S, Schochet S. Vascular contrast enhancement in Lhermitte-Duclos disease: case report. Neuroradiology 1995; 37: 545-548.

22. Rimbau J, Isamat F. Dysplastic gangliocytoma of the cerebellum (Lhermitte-Duclos disease) and its relation to the multiple hamartoma syndrome (Cowden disease). J Neurooncol 1994; 18: 191-197.

23. Sutphen R, Diamond TM, Minton SE, et al. Severe LhermitteDuclos disease with unique germline mutation of PTEN. Am $\mathrm{J}$ Med Genet 1999; 82: 290-293.

24. Thomas DW, Lewis MA. Lhermitte-Duclos disease associated with Cowden's disease. Int J Oral Maxillofac Surg 1995; 24: 369-371.

25. Vantomme N, Van Calenbergh F, Goffin J, et al. Lhermitte-Duclos disease is a clinical manifestation of Cowden's syndrome. Surg Neurol 2001; 56: 201-204; discussion 204-205.

26. Vinchon M, Blond S, Lejeune JP, et al. Association of LhermitteDuclos and Cowden disease: report of a new case and review of the literature. J Neurol Neurosurg Psychiatry 1994; 57: 699-704.

27. Vital A, Vital C, Martin-Negrier ML, et al. Lhermitte-Duclos type cerebellum hamartoma and Cowden disease. Clin Neuropathol 1994; 13: 229-231.

28. Wells GB, Lasner TM, Yousem DM, et al. Lhermitte-Duclos disease and Cowden's syndrome in an adolescent patient. Case report. J Neurosurg 1994; 81: 133-136.

29. Williams DW, 3rd, Elster AD, Ginsberg LE, et al. Recurrent Lhermitte-Duclos disease: report of two cases and association with Cowden's disease. AJNR Am J Neuroradiol 1992; 13: 287290.

30. Yuasa H, Motokishita T, Tokito S, et al. Lhermitte-Duclos disease associated with Cowden's disease--case report. Neurol Med Chir (Tokyo) 1997; 37: 697-700.

31. Simmons ML, Lamborn KR, Takahashi M, et al. Analysis of complex relationships between age, p53, epidermal growth factor receptor, and survival in glioblastoma patients. Cancer Res 2001; 61: 1122-1128.

32. Hildenbrand C, Burgdorf WH, Lautenschlager S. Cowden syndrome-diagnostic skin signs. Dermatology 2001; 202: 362366.

33. Starink TM, van der Veen JP, Arwert F, et al. The Cowden syndrome: a clinical and genetic study in 21 patients. Clin Genet 1986; 29: 222-233.

34. Tuli S, Provias JP, Bernstein M. Lhermitte-Duclos disease: literature review and novel treatment strategy. Can J Neurol Sci 1997; 24: 155-160.

35. Ambler M, Pogacar S, Sidman R. Lhermitte-Duclos disease (granule cell hypertrophy of the cerebellum) pathological analysis of the first familial cases. J Neuropathol Exp Neurol 1969; 28: 622-647.

36. Knobbe CB, Merlo A, Reifenberger G. PTEN signaling in gliomas. Neurooncol 2002; 4: 196-211.

37. Nelen MR, van Staveren WC, Peeters EA, et al. Germline mutations in the PTEN/MMAC1 gene in patients with Cowden disease. Hum Mol Genet 1997; 6: 1383-1387.

38. Knudson AG, Jr. Mutation and cancer: statistical study of retinoblastoma. Proc Natl Acad Sci U S A 1971; 68: 820-823.

39. Weary PE, Gorlin RJ, Gentry WC Jr, et al. Multiple hamartoma syndrome (Cowden's disease). Arch Dermatol 1972; 106: 682-690.

40. Schrager CA, Schneider D, Gruener AC, et al. Clinical and pathological features of breast disease in Cowden's syndrome: an underrecognized syndrome with an increased risk of breast cancer. Hum Pathol 1998; 29: 47-53. 
41. Sabin HI, Lidov HG, Kendall BE, et al. Lhermitte-Duclos disease (dysplastic gangliocytoma): a case report with CTand MRI. Acta Neurochir (Wien) 1988; 93: 149-153.

42. el Gammal T, Mark E, Brooks B. MR imaging of Chiari II malformation. AJR Am J Roentgenol 1988; 150: 163-170.

43. Marcus CD, Galeon M, Peruzzi P, et al. Lhermitte-Duclos disease associated with syringomyelia. Neuroradiology 1996; 38: 529-531.

44. Smoker WR, Keyes WD, Dunn VD, et al. MRI versus conventional radiologic examinations in the evaluation of the craniovertebral and cervicomedullary junction. Radiographics 1986; 6: 953-994.

45. Ishikawa M, Kikuchi H, Fujisawa I, et al. Tonsillar herniation on magnetic resonance imaging. Neurosurgery 1988; 22: 77-81.

46. Rainov NG, Holzhausen HJ, Burkert W. Dysplastic gangliocytoma of the cerebellum (Lhermitte-Duclos disease). Clin Neurol Neurosurg 1995; 97: 175-180.
47. Nowak DA, Trost HA, Porr A, et al. Lhermitte-Duclos disease (Dysplastic gangliocytoma of the cerebellum). Clin Neurol Neurosurg 2001; 103: 105-110.

48. Lyons CJ, Wilson CB, Horton JC. Association between meningioma and Cowden's disease. Neurology 1993; 43: 1436-1437.

49. Peters N, Wellenreuther R, Rollbrocker B, et al. Analysis of the PTEN gene in human meningiomas. Neuropathol Appl Neurobiol 1998; 24: 3-8.

50. Carbone F, Brihaye J, Drochmans P. [Parieto-occipital spongioblastoma, associated with dysplastic gangliocytoma of the cerebellum]. Acta Neurol Psychiatr Belg 1955; 55: 568-580.

51. Domingo Z, Fisher-Jeffes ND, de Villiers JC. Malignant occipital astrocytoma in a patient with Lhermitte-Duclos disease (cerebellar dysplastic gangliocytoma). Br J Neurosurg 1996; 10: 99-102. 